\title{
Expressão citofotométrica dos marcadores tumorais CD-34 e fator VIII no câncer de cólon
}

\section{Cytophotometric expression of the tumor markers CD-34 and factor VIII in colorectal cancer}

Cacilda Joyce Ferreira da Silva Garcia'; Ronaldo M. Cuenca²; Fabio Roberto Bora'; Jurandir Marcondes Ribas-Filho ${ }^{3}$; Nicolau Gregori Czeczko33; Carmen Australla Paredes Marcondes Ribas ${ }^{3}$; Jorge Wagenführ Jr. ${ }^{1}$

\section{R E S U M O}

\begin{abstract}
Objetivos: Verificar a posssibilidade de quantificar a expressão dos marcadores tumorais CD-34 e Fator VIII no câncer de cólon; verificar se existe superioridade entre um marcador e outro para estudo da angiogênese; verificar se há correlação na análise do índice de marcagem e a densidade óptica média nos marcadores utilizados. Métodos: Dezessete casos de adenocarcinoma colorretal recuperados de blocos de parafina e confirmados pela hematoxilina-eosina, foram submetidos à coloração imunoistoquímica pelo método da estreptoavidina-biotina-peroxidase e utilizados os marcadores tumorais CD-34 e Fator VIII. Após este processo as lâminas foram submetidas à leitura no sistema Samba $4000 ®$ e avaliadas pelo software Immuno®. Os parâmetros estudados foram: índice de marcagem e densidade óptica, expressos por médias, medianas, valores mínimos, valores máximos e desvios-padrão, analisados estatisticamente. Resultados: Para o marcador CD-34 não houve normalidade dos dados em relação ao índice de marcagem e houve para a densidade óptica. Para o Fator VIII, houve normalidade de dados em relação ao índice de marcagem e para a densidade óptica. Conclusão: Foi possível quantificar a expressão dos marcadores tumorais CD-34 e Fator VIII através do índice de marcagem e da densidade óptica média; não houve diferença entre os marcadores em relação à média do índice de marcagem e da densidade óptica, não sendo possível definir superioridade entre um e outro; não foi observada tendência à correlação quando comparados densidade óptica e índice de marcagem do Fator VIII e do CD-34 isoladamente estudados; não houve correlação entre o índice de marcagem do Fator VIII quando comparado com o CD-34, bem como a densidade óptica do Fator VIII com o CD-34.
\end{abstract}

Descritores: Citofotometria. Neoplasias colorretais. Agentes indutores da angiogênese. Fator VIII. Marcadores biológicos de tumor.

\section{INTRODUÇÃO}

O s tumores epiteliais malignos dos cólons são responsáveis por altas taxas de morbidade e mortalidade no mundo inteiro, sendo que acometem igualmente homens e mulheres, com predileção para a faixa etária dos 50 aos 70 anos. $O$ adenocarcinoma é o tipo histológico mais freqüente, representando $70 \%$ do total.

O desenvolvimento do câncer colorretal pode estar associado a fatores genéticos, além da obesidade, idade avançada, uso de tabaco e álcool, entre outros. Nos casos de polipose adenomatosa familiar as chances de desenvolvimento de neoplasia maligna é de $100 \%$ aos 50 anos.

A carcinogênese colorretal segue o modelo "seqüência adenoma-carcinoma", no qual lesões adenomatosas (benignas) sofrem alterações displásicas pro- gressivas, de cunho genético, culminando com a transformação maligna para adenocarcinoma.

Dentre os métodos utilizados para o estudo das neoplasias malignas, a aplicação da imunoistoquímica tem exibido resultados promissores. Múltiplos anticorpos, alguns específicos, têm sido capazes de identificar a histogênese tumoral, caracterizar produtos de secreção de células neoplásicas e, principalmente, avaliar os fatores prognósticos através da angiogênese por estar ela diretamente associada à progressão do tumor e metástases. O anticorpo CD-34 é um marcador de células hematopoiéticas primitivas e células endoteliais, portanto, qualquer estrutura celular isolada ou agrupada, com ou sem lúmen, quando imunomarcada pelo CD-34 é considerada um vaso sanguíneo. O Fator VIII é um anticorpo altamente específico para demonstração de células com diferenciação vascular. Estruturas celulares isoladas ou agrupadas, com ou sem lúmen,

Trabalho realizado no Instituto de Pesquisas Médicas do Hospital Universitário Evangélico de Curitiba / Faculdade Evangélica do Paraná, Curitiba, Paraná, Brasil.

1. Mestre do Programa de Pós-graduação em Princípios da Cirurgia pela Faculdade Evangélica do Paraná - Curitiba - PR - BR; 2. Doutor em Clínica Cirúrgica pela Universidade Federal do Paraná - Curitiba - PR - BR; 3. Doutor, Professor Permanente do Programa de Pós-graduação em Princípios da Cirurgia da Faculdade Evangélica do Paraná - Curitiba - PR - BR. 
quando imunomarcadas pelo Fator VIII são consideradas vasos sangüíneos.

Múltiplos trabalhos têm utilizado o Fator VIII e CD34 com bons resultados na avaliação tumoral em geral. Procurando melhorar a acurácia na avaliação de marcadores tumorais, as análises teciduais estão cada vez mais sendo feitas com o auxílio de softwares que ao digitalizarem as imagens possibilitam dados numéricos de células e tecidos neoplásicos tornando os resultados mais confiáveis'

Entre os utilizados, o Sistema de Análise Microscópica de Busca Automática (SAMBA) e software Immuno®, descrevem quantitativamente e qualitativamente (avaliação citofotométrica) diversos marcadores teciduais, através de diversos parâmetros.

Assim, este estudo, utilizando os marcadores tumorais CD-34 e Fator VIII no adenocarcinoma colorretal, tem por objetivos: 1. verificar a posssibilidade de quantificar a expressão dos marcadores tumorais CD-34 e Fator VIII no câncer de cólon; 2 . verificar se existe superioridade entre um marcador e outro para estudo da angiogênese; 3. verificar se há correlação na análise do índice de marcagem e a densidade óptica média nos marcadores utilizados.

\section{MÉTODOS}

O estudo foi desenvolvido no Instituto de Pesquisas Médicas do Hospital Universitário Evangélico de Curitiba/ Faculdade Evangélica do Paraná, Curitiba, PR, Brasil e aprovado pela Comissão de Ética em Pesquisa da Sociedade Evangélica Beneficente de Curitiba.

As amostras de peças cirúrgicas de doentes operados entre 2000 e 2003 foram provenientes do Serviço de Anatomia Patológica do Hospital das Forças Armadas, em Brasília - DF, e submetidas à revisão e seleção no Laboratório de Citologia e Histologia Ltda - CITOLAB, na cidade de Curitiba.

Após coloração imunoistoquímica com os marcadores teciduais CD-34 e Fator VIII, elas foram submetidas à avaliação computadorizada para análise do índice de marcagem e da densidade óptica de cada marcador.

A amostra inicial era de 60 blocos de parafina, entretanto após seleção, ficaram passíveis de estudo somente 17. O restante do material ou exibia pouco material tumoral ou não apresentava qualidade de processamento técnico adequado para imunoistoquímica, sendo estes os motivos de exclusão destas peças. Doze casos eram adenocarcinomas moderadamente diferenciados, três bem diferenciados e dois mucinosos.

Em seqüência, iniciou-se a técnica de coloração de rotina em hematoxilina-eosina para confirmação diagnóstica e depois a preparação imunoistoquímica

A imunoexpressão das proteínas CD-34 e Fator VIII foi obtida através do método imunoenzimático da streptoavidina-biotina-peroxidase.

Os cortes de tecido tumoral foram submetidos a dois meios de avaliação: microscopia óptica e sistema de análise microscópica de busca automática.
Para análise com microscopia óptica, em ambos os marcadores, os endotélios vasculares tanto da área tumoral quanto da normal (controle interno positivo), foram devidamente corados, o que confirmou a veracidade da reação.

Passou-se então para a seleção dos hot spots e, subjetivamente, o patologista procedeu a análise qualitativa avaliando a intensidade da coloração em cada campo microscópico quantificadas em +: fracamente positivo, ++ moderadamente positivo e +++ fortemente positivo.

Para a análise microscópica de busca automática, foi utilizado o sistema de citofotometria de imagem denominado SAMBA 4000® - Systeme d'Analyse Microscopique à Balayage Automatique (Sistema de Análise Microscópica de Busca Automática) fabricado pela Alcatel (Grenoble/França), e composto por um hardware capaz de captar imagens microscópicas e por um software com capacidade para interpretar e analisar matematicamente as imagens captadas.

O hardware foi composto por microscópio, vídeocâmera, microcomputador e impressora. O fluxo luminoso, oriundo da lâmpada de xenon, era controlado por potenciômetro capaz de avaliar com precisão a quantidade de luz que atravessava o condensador, a lâmina e a objetiva. Em seguida era separado em duas partes: a via destinada a permitir a observação visual por meio das oculares e a de captação de imagem por meio da câmera, que iria compor a imagem no monitor do computador.

A captura das imagens foi feita por meio de uma câmera colorida capaz de padronizar as cores verde, azul e vermelha (sistema RGB "red, green and blue"), de forma que trabalhe com o mesmo nível de captação determinado. A imagem captada por fotodiodos, foi transformada em pontos de imagem (pixel), com área equivalente a $0.16 \mu \mathrm{m}^{2}$ por ponto-imagem e enviada ao computador e impressora.

O software Immuno® transformava as imagens celulares coradas pela técnica de imunoistoquímica capturadas pela vídeo-câmera em matriz numérica e, a partir desta, calculava parâmetros matemáticos que permitiam a quantificação das áreas mais coradas.

A primeira etapa da análise computadorizada da imagem compreende a transformação da imagem capturada pela câmera de vídeo em imagem numerizada, o que é feito mediante atribuição de graduações de níveis cinza (0 a 255) para cada ponto de imagem. Este processo corresponde à numerização da imagem e envolve duas etapas: geração de matriz em níveis de cinza (Figura 1) e transformação desta em matriz numérica binária.

O valor 0 é conferido para o fundo não corado e os valores numéricos para os pontos da imagem corados e que apresentam densidade variável sendo representados em diferentes níveis de cinza codificados por números diferentes conforme a densidade tecidual no pixel estudado. A somatória destes pontos representa a densidade óptica integrada. 


\begin{tabular}{|l|}
0000000000000000000000000000000000000000000000000000000000000000000 \\
0000000000000000000000000000000000000000000000000000000000000000000 \\
0000000000000002520514536255100000000000000000000000000000000000 \\
00000000000026354161781052531422500000000000000000000000000000 \\
000000000000354241022002032002035000000000000000000000000000 \\
0000000000035238117869578105141204350000000000000000000000000 \\
0000000000023961183549469276664526000000000000000000000000000 \\
000000000000001017655668594364825400000000000000000000000000000 \\
0000000000000000001111816354256890000000000000000000000000000000 \\
00000000000000000000002513551860000000000000000000000000000000000 \\
0000000000000000000000000000000000000000000000000000000000000000000 \\
0000000000000000000000000000000000000000000000000000000000000000000
\end{tabular}

Figura 1 - Ilustração do processo de numerização da imagem em níveis de cinza de um núcleo celular, mostrando que cada pixel se transforma em número com maior ou menor concentração na marcação.

Da mesma forma, pode-se identificar regiões hipo e hipercromáticas. Valores inferiores a 64 ,caracterizam regiões pálidas; entre 64 e 128, pouco densas; entre 128 e 192 moderadamente densas; e com valores superiores a 192, são consideradas hipercromáticas.

A obtenção destes dados foi realizada automaticamente pelo programa do sistema SAMBA $4000 \AA$.

\section{Procedimento de leitura}

A etapa inicial foi a calibragem do sistema SAMBA $4000 \circledast$ assim efetuada: aquisição da imagem; processamento e digitalização dela; binarização e segmentação da imagem; identificação do objeto; seleção e reconhecimento do objeto de interesse; análise da imagem e impressão dos resultados.

Todas as lâminas foram estudadas segundo a técnica de varredura por campos em barra grega. Realizou-se a seleção de áreas com maior densidade tumoral, denominadas hot spots, fugindo de áreas com necrose tumoral, tecido normal ou mesmo de artefatos. A análise foi realizada em dez campos de cada lâmina, variando a área estudada de 60 a 120 mil $\mu^{2}$. Após a leitura de cada campo, os resultados foram armazenados cumulativamente em diretório específico (identificação de amostra tumoral).

Ao final da captação das imagens de cada amostra tumoral, o software editou uma tabela de quick statistics listando o índice de marcagem e a densidade óptica de cada amostra. A densidade óptica refere-se à concentração do marcador (anticorpo) na célula, em um determina- do campo analisado e o índice de marcagem quantifica a superfície do tecido que foi corada pelo marcador tecidual.

Os resultados obtidos foram expressos por médias, medianas, valores mínimos, valores máximos e desviospadrão. A condição de normalidade das variáveis quantitativas foi investigada usando-se o teste de Shapiro-Wilks. Para a comparação da expressão dos marcadores foi usado o teste $t$ de Student para amostras dependentes ou o teste não-paramétrico de Wilcoxon. Para avaliar a correlação entre os marcadores estimou-se o coeficiente de correlação de Pearson ou o de Spearman, quando apropriado. Valores de $P<0,05$ indicaram significância estatística.

\section{RESULTADOS}

Na tabela 1 são apresentados os resultados estatísticos do índice de marcagem e densidade óptica dos marcadores CD-34 e Fator VIII. Observa-se que o índice de marcagem e a densidade ótica média foram semelhante para os marcadores utilizados:

\section{CD-34 \\ Expressão do marcador}

À microscopia óptica, observa-se os cortes histológicos corados por fundo azulado, proveniente da coloração pela hematoxilina, entremeado por estruturas celulares de coloração castanho-dourada, interpretadas como positivas para imunoexpressão do anticorpo utilizado. A pigmentação castanho-dourada representa a ação

Tabela 1 - Resultados de médias, mediana, valores mínimos, valores máximos e desvios-padrão das expressões dos marcadores CD-34 e Fator VIII

\begin{tabular}{lcccccr}
\hline Variável & $\mathbf{n}$ & Média & Mediana & Mínimo & Máximo & Desvio-Padrão \\
\hline Índice de marcagem do CD-34 & 17 & 66,07 & 71,70 & 12,02 & 92,38 & 21,12 \\
Densidade óptica do CD-34 & 17 & 44,13 & 44,63 & 31,07 & 65,82 & 8,70 \\
Índice de marcagem do Fator VIII & 17 & 61,06 & 61,55 & 36,62 & 85,92 & 11,60 \\
Densidade óptica do Fator VIII & 17 & 47,43 & 46,90 & 35,62 & 60,86 & 6,70 \\
\hline
\end{tabular}

CD-34. 
do cromógeno diaminobenzidina, utilizado na técnica imunoistoquímica para reagir com a peroxidase da Streptoavidina e, com isto, evidenciar a positividade da reação imunoistoquímica (Figura 2A).

O controle interno positivo que garante que a reação imunoistoquímica alcançou o objetivo, se mostra com a coloração castanho-dourada de estruturas sabidamente vasculares no próprio estroma tumoral (Figura 2B).

\section{Distribuição de freqüência do índice de marcagem e da densidade óptica}

Na tabela 2 são apresentados os resultados das distribuições de freqüência do índice de marcagem do CD34, divididos em 5 grupos da seguinte maneira: até 20; 20,01 a 40; 40,01 a 60; 60,01 a 80 e 80,01 a 100.

Testou-se a hipótese nula de que os dados têm distribuição normal, versus a alternativa de que eles não a

Tabela 2 - Distribuição de freqüência do índice de marcagem* e densidade óptica** do CD-34.

\begin{tabular}{lcc}
\hline Indice de Marcagem & Freqüência & Percentual \\
\hline Até 20 & 1 & 5,88 \\
20,01 a 40 & 1 & 5,88 \\
40,01 a 60 & 1 & 5,88 \\
60,01 a 80 & 10 & 58,82 \\
80,01 a 100 & 4 & 23,53 \\
Total & 17 & 100 \\
\hline Densidade Óptica & Freqüência & Percentual \\
\hline 30,01 a 40 & 6 & 5,56 \\
40,01 a 50 & 8 & 16,67 \\
50,01 a 60 & 2 & 22,22 \\
60,01 a 70 & 1 & 22,22 \\
Total & 17 & 100 \\
\hline
\end{tabular}

*Condição de normalidade: $\mathrm{P}=0,014$ (Teste de Shapiro-Wilks).

${ }^{*}$ Condição de normalidade: $\mathrm{P}=0,518$ (Teste de Shapiro-Wilks). têm. Os resultados indicaram que para o marcador tumoral CD-34 $(p=0,014)$ não há normalidade dos dados para o índice de marcagem nos grupos estudados.

Ainda na tabela 2 são apresentadas as distribuições de freqüência da densidade óptica do marcador CD34 distribuídas da seguinte maneira: de 30,01 a 40; de 40,01 a 50; de 50,01 a 60; de 60,01 a 70 .

Testou-se a hipótese nula de que os dados têm distribuição normal versus a alternativa de que eles não a têm. Os resultados indicaram que para a densidade óptica não foi rejeitada a condição de normalidade dos dados para os grupos de estudo $(p=0,518)$.

\section{Fator VIII \\ Expressão do marcador}

À microscopia óptica, os cortes histológicos ficaram corados por fundo azulado, proveniente da coloração pela hematoxilina, com as estruturas celulares que são positivas para o anticorpo Fator VIII coradas em castanho-dourado, devido a ação do cromógeno diaminobenzidina utilizado na técnica imunoistoquímica para reagir com a peroxidase da Streptoavidina (Figura 3A)

$O$ controle interno positivo que garante que a reação imunoistoquímica alcançou o objetivo, mostrou-se com a coloração castanho-dourada de estruturas sabidamente vasculares no próprio estroma tumoral (Figura 3B).

\section{Distribuição de freqüência do índice de marcagem e da densidade óptica}

$\mathrm{Na}$ tabela 3 são apresentados os resultados das distribuições de freqüência do índice de marcagem divididos em seis grupos da seguinte maneira: de 30,01 a 40; de 40,01 a 50; de 50,01 a 60; de 60,01 a 70; de 70,01 a 80; de 80,01 a 90 .

Testou-se a hipótese nula de que os dados têm distribuição normal, versus a alternativa de que eles não a têm. Os resultados indicaram que para o índice de marcagem não foi rejeitada a condição de normalidade dos dados para os grupos de estudo $(p=0,998)$.
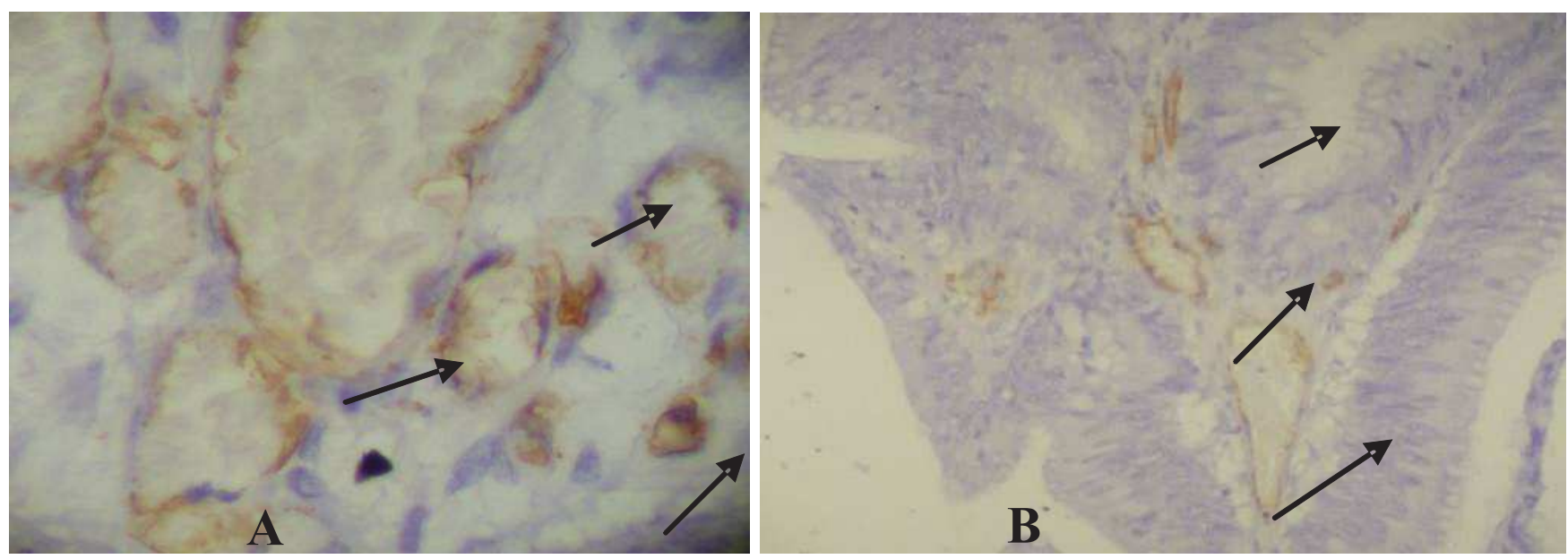

Figura 2 - Corte histológico de adenocarcinoma colorretal imunocorado pelo anticorpo CD-34 (aumento 1000x). Em A, as setas indicam vasos neoformados no estroma tumoral e em B, controles internos positivos. 

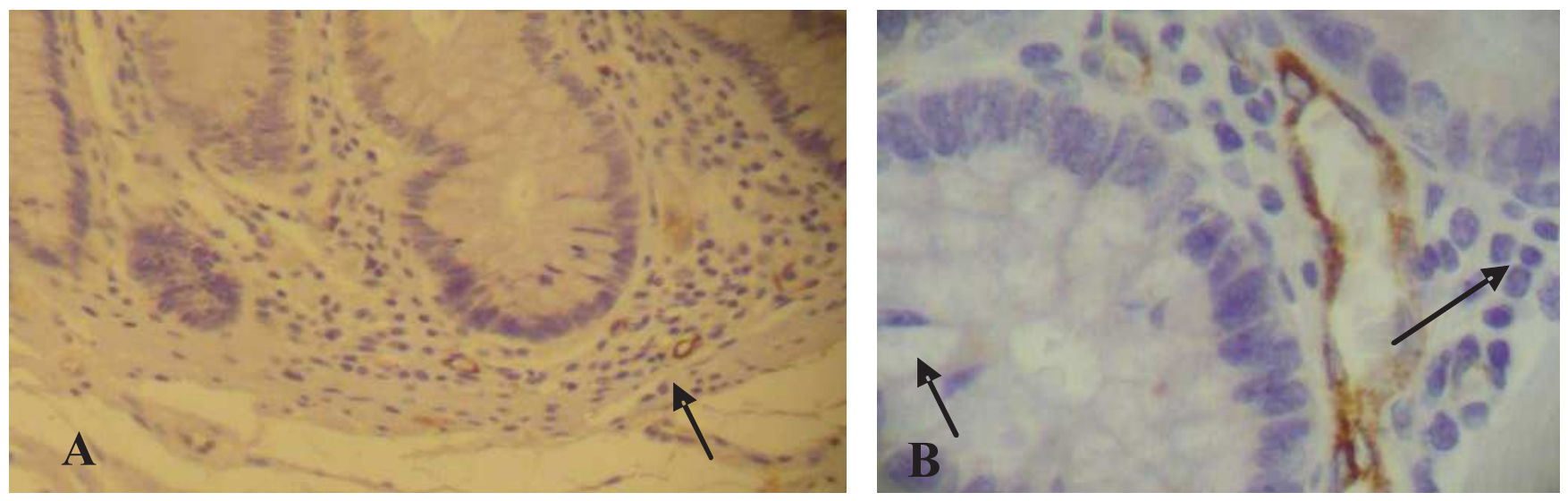

Figura 3 - Corte histológico de adenocarcinoma colorretal imunocorado pelo anticorpo Fator VIII (aumento 400x). Em A, as setas mostram vasos neoformados no estroma tumoral e em B, controle interno positivo - vaso sanguineo pré-existente no estroma tumoral.

Tabela 3 - Resultado da distribuição de freqüência do índice de marcagem* e densidade óptica** do marcador Fator VIII.

\begin{tabular}{lcc}
\hline Indice de Marcagem & Freqüência & Percentual \\
\hline 30,01 a 40 & 1 & 5,88 \\
40,01 a 50 & 1 & 5,88 \\
50,01 a 60 & 6 & 35,29 \\
$60 ; 01$ a 70 & 6 & 35,29 \\
70,01 a 80 & 2 & 11,76 \\
80,01 a 90 & 1 & 5,88 \\
Total & 17 & 100 \\
\hline Densidade Optica & Freqüência & Percentual \\
\hline 35,00 a 40 & 2 & 11,76 \\
40,01 a 45 & 2 & 11,76 \\
45,01 a 50 & 9 & 52,94 \\
50,01 a 55 & 1 & 5,88 \\
55,01 a 60 & 2 & 11,76 \\
60,01 a 65 & 1 & 5,88 \\
Total & 17 & 100
\end{tabular}

*Condição de normalidade: $\mathrm{P}=0,998$ (Teste de Shapiro-Wilks). ${ }^{*}$ Condição de normalidade: $\mathrm{P}=0,432$ (Teste de Shapiro-Wilks).

Ainda na tabela 3 é apresentada a distribuição das freqüências da densidade óptica do Fator VIII da seguinte maneira: de 35,00 a 40; de 40,01 a 45; de 45,01 a 50; de 50,01 a 55; de 55,01 a 60; de 60,01 a 65, mostrando que para a densidade óptica não foi rejeitada a condição de normalidade dos dados, visto que foi obtido $p=0,432$.

\section{Comparação entre as expressões dos marcadores CD-34 e Fator VIII}

Testou-se a hipótese nula de que os resultados do índice de marcagem são iguais para ambos versus a alternativa de que eles são diferentes. Na tabela 4 são apresentados os valores de média, mediana, valores mínimos, valores máximos e desvio-padrão do índice além da diferença encontrada entre eles. O resultado estatístico indicou a não rejeição da hipótese nula $(p=0,093)$. Sendo assim, não se pode afirmar que existe diferença significativa entre os marcadores em relação ao índice de marcagem.

Testou-se a hipótese nula de que as médias da densidade óptica são iguais para os marcadores versus a alternativa de que as elas são diferentes. Na tabela 4 são apresentados os valores de média, mediana, valores mínimos, valores máximos e desvio-padrão da densidade óptica e também a diferença entre eles. O resultado do teste estatístico indicou a não rejeição da hipótese nula $(p<0,001)$. Sendo assim, não se pode afirmar que existe diferença significativa entre os marcadores em relação à densidade óptica.

\section{Correlação entre as expressões da densi-} dade óptica e índice de marcagem

Para avaliar o grau de associação entre as expressões foram estimados os coeficientes de correlação entre elas. Em cada situação testou-se a hipótese nula de ausência de correlação versus a alternativa da existência (Tabela 5).

Os resultados estatísticos indicaram que para o marcador CD-34 não existe correlação entre a densidade óptica e o índice de marcagem, pois o $P$ obtido foi igual a 0,286, o mesmo ocorrendo com o Fator VIII $(p=0,276)$

Comparando-se os marcadores entre si tanto no índice de marcagem $(p=0,866)$ como na densidade óptica $(p=0,497)$ mostra-se que não houve correlação significativa entre eles.

\section{DISCUSSÃO}

Sabe-se que o epitélio normal do intestino sofre contínua renovação entre 3 e 5 dias, e que a progressão da mucosa normal para a neoplásica pode durar 10 anos e que o câncer colorretal é processo multi-estádio, em que as várias alterações genéticas levariam anos para acontecer $^{2}$.

A instabilidade genômica, característica inerente aos tumores relacionados a erros de replicação do DNA, tem sido particularmente estudada no câncer colorretal. 
Tabela 4 - Valores estatisticos do índice de marcagem* e densidade óptica* * dos marcadores CD-34 e Fator VIII e a diferença entre ambos.

\begin{tabular}{lcrrrrrr}
\hline Variável & $\mathrm{n}$ & Média & Mediana & Mínimo & Máximo & Desvio Padrão Valor de $p^{*}$ \\
\hline Índice de marcagem do CD-34 & 17 & 66,07 & 71,70 & 12,02 & 92,38 & 21,12 \\
Índice de marcagem do Fator VIII & 17 & 61,06 & 61,55 & 36,62 & 85,92 & 11,60 & 24,63 \\
Diferença entre O Fator VIII e CD-34 & 17 & $-5,01$ & $-12,76$ & $-30,83$ & 60,83 & 0,093 \\
\hline Variável & $\mathrm{n}$ & Média & Mediana & Mínimo & Máximo & Desvio Padrão Valor de $p^{*}$ \\
\hline Densidade óptica do CD-34 & 17 & 44,13 & 44,63 & 31,07 & 65,82 & 8,70 \\
Densidade óptica do Fator VIII & 17 & 47,43 & 46,90 & 35,62 & 60,86 & 6,70 & 9,99 \\
Diferença entre o Fator VIII e o CD-34 & 17 & 3,30 & 2,32 & $-19,66$ & 20,77 & 0,192 \\
\hline
\end{tabular}

(*) Teste não-paramétrico de Wilcoxon $(\mathrm{P}<0,05)$.

(**) Teste $t$ de Student para amostras pareadas $(\mathrm{P}<0,05)$.

Tabela 5 - Coeficientes de correlação entre as expressões dos marcadores CD-34 e Fator VIII.

\begin{tabular}{llcc}
\hline Variáveis & $\mathrm{n}$ & Coeficiente de Correlação & Valor de $p$ \\
\hline Índice de marcagem do CD-34 x densidade óptica do CD-34 & 17 & $0,274^{*}$ & 0,286 \\
Índice de marcagem do Fator VIII x densidade óptica do Fator VIII & 17 & $0,280^{* *}$ & 0,276 \\
Índice de marcagem do CD-34 x índice de marcagem do Fator VIII & 17 & $0,044^{*}$ & 0,866 \\
Densidade óptica do CD-34 x densidade óptica do Fator VIII & 17 & $0,177^{*}$ & 0,497 \\
\hline
\end{tabular}

\footnotetext{
* Coeficiente de correlação de Spearman.
}

** Coeficiente de correlação de Pearson.

Pinho $^{3}$ analisou 50 artigos sobre ele e os aspectos relativos à biologia molecular. Apresentou lista de marcadores tumorais já estudados concluindo que existe dificuldade para definir o perfil genômico tumoral desse tumor, haja vista que a maior parte dos marcadores estudados comportamse como fatores prognósticos independentes em diferentes etapas da carcinogênese (proliferação celular, angiogênese, adesão ou invasão tumoral). Por outro lado, muitos marcadores desempenham papéis diferentes no ambiente celular quando estudados isoladamente ou interagindo com outros marcadores. Desta maneira, concluiu que ainda não existe definição sobre um "marcador prognóstico universal" para o câncer colorretal.

Nota-se que existe dinamismo na renovação celular da mucosa colônica, diretamente relacionado à concentração de várias proteínas que atuam sobre o ciclo celular. Muito se tem estudado em relação à tumorigênese e a progressão do adenocarcinoma colorretal. Um salto qualitativo ficou evidente a partir da aplicação de novos recursos diagnósticos e prognósticos, como por exemplo, a imunoistoquímica, ferramenta que tem permitido demonstrar a concentração e a expressão de proteínas na mucosa colônica, bem como relacioná-las com aspectos histológicos e histopatológicos.

Apesar de o adenocarcinoma colorretal ser tipo histológico facilmente encontrado nos acervos de laboratórios de anatomia patológica, selecionar amostras com conteúdo tumoral adequado à avaliação imunoistoquímica tornou-se tarefa árdua no presente estudo. Dos 60 casos inicialmente selecionados, 17 somente foram viáveis, pois os demais ou exibiam pouca amostra tumoral ou artefatos técnicos que inviabilizaram a imunomarcação. Esses artefatos principalmente estavam relacionados à inativação dos receptores antigênicos decorrentes de exposição prolongada ao formol a $10 \%$ durante o processo de fixação tecidual. Houve aproveitamento pequeno de $28,33 \%$ do total de blocos servindo este dado com alerta para quem quizer estudar imunoistoquimicamente material de arquivo.

Para realização desta pesquisa foram utilizadas lâminas para técnica hematoxilina-eosina e para imunoistoquímica. As primeiras foram utilizadas para submeter todo o material de estudo à validação dos diagnósticos previamente estabelecidos pelo serviço de origem.

A interpretação imunoistoquímica foi realizada utilizando-se o sistema SAMBA $4000 \AA$ que permite calcular parâmetros matemáticos nas imagens microscópicas. Ele não substitui o patologista, mas sim vem auxiliá-lo com dados objetivos no que muitas vezes o olho humano não tem condições de fazer. Para melhor aproveitamento das imagens em cada lâmina utilizaram-se os lugares de maior ação do marcador ou hot spots. Este processo é válido e usualmente utilizado por permitir análise de maior quantidade de expresão do marcador.

Já foi demonstrado que fatores específicos produzidos pelas células tumorais induzem a formação de novos vasos no hospedeiro ${ }^{4}$ e que o número de vasos neoformados poderia ser utilizado como fator prognóstico ${ }^{5}$. Fase inicial sem neovascularização está associada à ausência de metástases e onde a neovascularização é crescente há correlação com sua presença ${ }^{5}$. Os tumores malignos dependem da angiogênese local para sua proliferação e metastatização ${ }^{6}$, contudo ela ocorre também em situações 
fisiológicas ou não neoplásicas quando maior aporte de irrigação sanguínea é necessário. Exemplos são a maturação de folículos ovarianos e formação de corpos lúteos, reparo de feridas, osteoartrites e nas doenças inflamatórias ${ }^{7}$. A angiogênese no adenocarcinoma colorretal ocorreria durante a transição do processo hiperplásico para neoplásico, portanto antecederia o desenvolvimento da neoplasia propriamente dita ${ }^{8}$.

Baseando-se na importante relevância da quantificação da angiogênese tumoral, atualmente várias pesquisas convergem para o desenvolvimento de drogas anti-angiogênicas, que seriam utilizadas na aplicação prática da oncologia clínica, para o tratamento dos mais diversos tipos de neoplasia. A estratégia futura para o tratamento das neoplasias deverá avaliar não só as células tumorais por si, mas principalmente o ambiente que envolve o tumor, onde a avaliação angiogênica é fator determinante. As drogas atuariam, por exemplo, induzindo a apoptose (morte celular programada), não só nas células tumorais mas também nas do endotélio vascular, impedindo a progressão tumoral $^{9}$, ou de recidiva ${ }^{10}$. Já está demonstrado que a presença do tumor primário determina redução da vascularização nas metástases distantes e que a sua ressecção, resultaria em aumento da vascularização das lesões metastáticas ${ }^{10}$. A causa disto não está ainda bem definida.

Os marcadores tumorais têm despertado grande interesse por serem ferramentas auxiliares principalmente no estudo diagnóstico e prognóstico das doenças neoplásicas. Há dois tipos de marcadores, os prognósticos e os preditivos. Os prognósticos indicam a probabilidade de ocorrer recidiva tumoral, bem como auxiliam na análise da sobrevida do paciente. Já os preditivos, apontam a probabilidade de resposta a uma terapia específica. Alguns marcadores são auxiliares na confirmação do tecido de origem da neoplasia (histogênese tumoral), no caso de neoplasia metastáticas ou pouco diferenciadas. Os marcadores de condições pré-malignas são igualmente úteis, pois servem como base para estratégias de screening ou para detectar populações de alto risco para o câncer, que possam se beneficiar com medidas preventivas. É importante ressaltar que nem todos os marcadores são específicos de um tumor, no sentido de que sua expressão seja restrita às células tumorais ${ }^{11}$.

Em condições normais, existe nos tecidos um equilíbrio entre as moléculas pró-angiogênicas e antiangiogênicas, em favor destas. Quando o equilíbrio é rompido, por exemplo nas neoplasias, desencadeia-se a angiogênese, e, clinicamente, verifica-se a expansão da massa tumoral.

Sabendo-se que os fatores angiogênicos atuam sobre os receptores específicos nos tecidos, desenvolveramse técnicas que possibilitam o estudo destes receptores através de anticorpos marcados contra os mesmos, sendo possível determinar quantitativamente a expressão dos receptores angiogênicos.

Dentre os imunomarcadores mais utilizados para avaliar a densidade microvascular nos tecidos em geral, pode-se citar o fator de crescimento endotelial vascular (VEGF), CD-31, CD-34 e Fator VIII. Os três últimos são considerados panendoteliais, e não são específicos para os vasos neoformados e sim para todas as paredes vasculares, as já presentes no tecido tumoral e as neoformadas ${ }^{12}$. Assim há espaço para investigações futuras no sentido de desenvolver marcadores tumorais mais específicos para quantificar melhor microvasos neoformados.

No presente ensaio, buscou-se avaliar a melhor performace de dois anticorpos monoclonais panendoteliais, o CD-34 e o Fator VIII, para a quantificação de microvasos no estroma de adenocarcinoma colorretal.

Trabalhos interessantes para a avaliação da angiogênese no câncer colorretal utilizaram como único marcador o anticorpo CD-34 obtendo boa imunomarcação e afirmando que ele seria útil para a avaliação da densidade microvascular. Além da imunomarcação de células endoteliais, observa-se a expressão dele também em células estromais denominadas células intersticiais dendríticas, as quais encontram-se distribuídas em quase todos os tecidos orgânicos ${ }^{3,8}$. Em tecido normal, a maioria dos fibroblastos estromais são positivos para o CD-34. Já no adenocarcinoma, cujo estroma é desmoplásico, ocorre ausência de marcação do anticorpo nas células estromais, ficando apenas nas paredes vasculares ${ }^{13}$.

Correlacionando-se os parâmetros densidade óptica e índice de marcagem do CD-34, observou-se que não houve associação significativa entre ambos, ou seja, uma lâmina poderá ter alto índice de marcagem e ao mesmo tempo apresentar ou não grande concentração deste imunomarcador.

Os dados na presente amostra sugerem que há proliferação de microvasos, o que comprova a atividade angiogênica no estroma peritumoral.

Em relação ao Fator VIII verificou-se que, para ambos os parâmetros, existiu normalidade dos dados, ou seja, em cada lâmina observou-se grande extensão da superfície imunocorada (índice de marcagem), bem como considerável concentração deste anticorpo (densidade óptica).

Na comparação entre CD-34 e Fator VIII em relação ao índice de marcagem a análise estatística mostrou que não se pode afirmar que exista diferença significativa entre os anticorpos, pois a média para o Fator VIII foi de $61,06 \%$ e para o CD-34 de 66,07\%.

Para o parâmetro densidade óptica, a análise estatística também indicou que não se pode afirmar que exista diferença significativa entre os anticorpos, uma vez que a média para o Fator VIII foi de 47,43 pixels e para o CD-34 de 44, 13 .

Diante destes dados, pode-se deduzir que, no presente estudo, ambos os anticorpos demonstraram imunocorar o endotélio vascular de maneira muito semeIhante, não havendo como afirmar que um deles imunomarcou com mais eficiência que o outro.

Estudos sobre a densidade microvascular sugeriram melhor imunomarcação e especificidade do Fator VIII 
para as células endoteliais quando comparado ao CD-34 em razão de que este também coraria leucócitos, células inflamatórias e microvasos linfáticos. Em contrapartida, o anticorpo Fator VIII seria mais específico para células endoteliais ${ }^{13}$.

Barra $^{14}$ esclarece que a técnica de imunoistoquímica ainda necessita de prudência para que seja amplamente utilizada, pois envolve fatores variados, externos ou não à amostra tecidual como, por exemplo, informações clínicas, adequado processamento tecidual, acondicionamento da amostra e qualidade de reagentes.

Há que se considerar que a maioria dos laboratórios de patologia já realizam exames imunoistoquímicos, nem sempre com ferramentas que garantam um rígido controle de qualidade e, o que seria mais preocupante, a imunocoloração é avaliada utilizando-se critérios subjetivos, como a quantificação em cruzes da densidade de coloração do marcador tecidual que varia muito de observador para observador.

$\mathrm{Na}$ tentativa de substituir o processo subjetivo de análise de marcadores teciduais para uma avaliação mais objetiva, sistemas de computador acoplados a microscópios e vídeocâmaras estão sendo utilizados, inicialmente em centros de pesquisa. Dentre eles o aqui utilizado interpreta e quantifica matematicamente as imagens dos marcadores teciduais captadas pela vídeo-câmera acoplada ao microscópio.

No presente estudo foi possível avaliar dois dos parâmetros matemáticos oferecidos pelo SAMBA, o índice de marcagem e a densidade óptica tendo sido possível quantificar a expressão dos marcadores, bem como comparálos e correlacioná-los com objetividade.

O estudo citofotométrico tem oferecido diversas oportunidades para pesquisadores e deverá em futuro próximo ser mais correntemente utilizado na prática clínica.

O presente estudo mostrou que: foi possível quantificar a expressão dos marcadores tumorais CD-34 e Fator VIII através do índice de marcagem e da densidade óptica média; não houve diferença entre os marcadores em relação à média do índice de marcagem e da densidade óptica, não sendo possível definir superioridade entre um e outro; não foi observada tendência à correlação quando comparados densidade óptica e índice de marcagem do Fator VIII e do CD-34 isoladamente estudados; não houve correlação entre o índice de marcagem do Fator VIII quando comparado com o CD-34, bem como a densidade óptica do Fator VIII com o CD-34.

\title{
A B S S T R A C T
}

\begin{abstract}
Objectives: In colorectal cancer, to describe the cytophotometric expression of the CD-34 and Factor VIII; to evaluate the degree of correlation between them; and to compare the CD-34 and Factor VIII expressions in relationship to label index and optical density. Methods: Seventeen cases of colorectal adenocarcinoma recovered from paraffin-embedded archival tissue and confirmed by hematoxilin-eosin staining, were submitted to streptavidin-biotin-peroxidase immunohistochemical method. In this process was used the tumor markers CD-34 and Factor VIII. The obtained slides were analysed using the SAMBA 4000® system with Immuno ${ }^{\circledR}$ software. The results were evaluated into two parameters: label index and optical density, and expressed by averages, medians, minimum values, maximum values, and standard deviation values. The normality condition of the quantitative variables was investigated by using the Shapiro-Wilks test. In order to evaluate the degree of association between the expressions of the markers, Pearson's Correlation Coefficient or Spearman's Correlation Coefficient were applied. To evaluate the comparison degree of the markers expression, Student's $t$ test or Wilcoxon's no parametric test were used. Results: For the CD-34 there was no data normality for the label index and there was normality in the optical density. For the Factor VIII, there was data normality for the label index and for the optical density. Conclusion: When the expressions of CD-34 and Factor VIII markers were correlated, there was no difference between them in relationship to the average label index and average optical density. When the expressions of the CD-34 and Factor VIII were compared, there was no correlation between the two variables.
\end{abstract}

Key words: Cytophotometry. Colorectal neoplasms. Angiogenesis inducing agents. Factor VIII. Tumor markers biological.

\section{REFERENCIAS}

1. Jonker A, Geerts WJ, Chieco P, Moorman AF, Lamers WH, Van Noorden CJ. Basic strategies for valid cytometry using image analysis Histochem J. 1997; 29(5):347-64.

2. Church J. Colon cancer screening update and management of the malignant polyp. Colon Cancer. 2005; 18(3):141-9.

3. Pinho MSL. Biologia molecular no câncer colorretal: um corte atual na literatura. Rev Bras Coloproct. 2002; 22(4):284-8.
4. Greenblatt M, Shubi P. Tumor angiogenesis: transfilter diffusion studies in the hamster by the transparent chamber technique. J Natl Cancer Inst. 1968; 41(1):111-24.

5. Srivastava A, Laidler P, Hughes LE, Woodcock J, Shedden EJ. Neovascularization in human cutaneous melanoma: a quantitative morphological and Doppler ultrasound study. Eur J Cancer Clin Oncol. 1986; 22(10):1205-9

6. Folkman J, Watson K, Ingber D, Hanahan D. Induction of angiogenesis during the transition from hyperplasia to neoplasia. Nature. 1989; 339(6219):58-61. 
7. Knighton DR, Fiegel VD, Phillips GD. The assay of angiogenesis Prog Clin Biol Res. 1991; 365:291-9.

8. Ravazoula P, Zolota V, Hatjicondi O, Sakellaropoulos G, Kourounis $\mathrm{G}$, Maragoudakis ME. Assessment of angiogenesis in human cervical lesions. Anticancer Res. 1996; 16(6B):3861-4.

9. Kerbel RS. Tumor angiogenesis: past, present and the near future Carcinogenesis. 2000; 21(3):505-15.

10. Graça B, Lunet C, Coelho AS, Monteiro G, Freire P, Speidel A, Carvalho L. Angiogénese e Cancro da biopatologia à terapêutica. Acta Med Port. 2004; 17:76-93.

11. National Cancer Institute [homepage on internet]. Bethesda: National Institutes of Health. Diagnostics Research: New Markers for Prediction and Prognosis. [updated 2007 July 24; cited 2008]. Available from: http://cancerdiagnosis.nci.nih gov ].

12. Akagi $K$, Ikeda $Y$, Sumiyoshi $Y$, Kimura $Y$, Kinoshita J, Miyazaki M, Abe T. Estimation of angiogenesis with anti-CD105 immunostaining in the process of colorectal cancer development. Surgery. 2002; 131(1 Suppl):S109-13.
13. Nakayama H, Enzan H, Miyazaki E, Kuroda N, Naruse K, Hiroi M. Differential expression of CD-34 in normal colorectal tissue, peritumoral inflammatory tissue, and tumour stroma. J Clin Pathol. 2000; 53(8):626-9.

14. Barra MB. O uso da imunoistoquímica no diagnóstico: indicações e limitações. Rev AMRIGS. 2006; 50(2):173-84.

Recebido em 04/09/2008

Aceito para publicação em 12/11/2008

Conflito de interesse: nenhum

Fonte de financiamento: nenhuma

\section{Como citar este artigo:}

Garcia CJ, Cuenca RM, Bora FR, Ribas-Filho JM, Czeczko NG, Ribas CA, Wagenführ Jr J. Expressão citofotométrica dos marcadores tumorais CD-34 e fator VIII no câncer de cólon. Rev Col Bras Cir. [periódico na Internet] 2009; 36(1). Disponível em URL: http://www.scielo.br/rcbc

\section{Endereço para correspondência:}

Cacilda Joyce Ferreira da Silva Garcia.

E-mail: ipem@evangelico.org.br 